\title{
A comparative study of intracervical Foley's catheter and intracervical PGE2 gel for pre-induction cervical ripening
}

\author{
Sunita Murmu*, Chetna Dwivedi
}

Department of Obstetrics and Gynecology, Tata Main Hospital, Jamshedpur, Jharkhand, India

Received: 10 May 2018

Accepted: 29 June 2018

*Correspondence:

Dr. Sunita Murmu,

E-mail: sunita.murmu@ tatasteel.com

Copyright: () the author(s), publisher and licensee Medip Academy. This is an open-access article distributed under the terms of the Creative Commons Attribution Non-Commercial License, which permits unrestricted non-commercial use, distribution, and reproduction in any medium, provided the original work is properly cited.

\section{ABSTRACT}

Background: Induction of labor is a common procedure in obstetrics. It is usually performed when risk of continuing a pregnancy is more than benefit of delivery. Cervical ripening has got a close relationship with the success rate of delivery. Although there are many methods for cervical ripening, in this study Foley's catheter and intra-cervical PGE2 gel are compared for labor induction and cervical ripening.

Methods: This is a prospective randomized comparative study, undertaken in the department of obstetrics and gynecology, Tata Main Hospital, Jamshedpur. 70 cases in which labor was induced with Foley's catheter were compared to other 70 cases who were induced with PGE2 gel.

Results: The commonest indication for induction in Foley's and PGE2 gel group was pregnancy induced hypertension. There was significant increase in the post induction Bishop's score in both the groups. The induction to delivery interval was significantly lower in Foley's group as compared to PGE2 group $(p<0.0001)$. Neonatal outcomes were comparable in both groups. Incidence of side effects were more in PGE2 group.

Conclusions: Foley's catheter is safe and effective method for induction of labor compared to PGE2 gel with significant improvement in Bishop's score and shorter induction delivery interval.

Keywords: Foley's catheter, Induction of labor, PGE2gel

\section{INTRODUCTION}

Labor is usually induced for maternal or fetal indications. Inductions without maternal or fetal indication or elective inductions, recently have been on the rise. ${ }^{1}$ The success of labor induction depends on cervical status at the time of induction. ${ }^{2}$ It is generally predicted that patients with a poor Bishop's score $\leq 3$ have unacceptably higher rates of failure of induction and are associated with increased rates of cesarean sections, maternal fever and fetal asphyxia. $^{3}$

Many women who undergo labor induction do not have a favorable cervix, so some methods of cervical ripening either pharmaceutical or mechanical were often used. The mechanical methods stimulate the endogenous prostaglandin production, thus ripening the cervix. Mechanical methods were the first method developed to ripen the cervix and induce labor. During recent decades they have been substituted by pharmacological methods. Potential advantages of mechanical methods compared with pharmacological methods, include simplicity of preservation, lower cost and reduction of the side effects.

Embrey and Mollison first described the use of a transcervical Foley's catheter for the cervical ripening. ${ }^{4}$ Currently Foley's catheter balloon is the most commonly used mechanical device for labor induction. ${ }^{5}$ The use of Foley's catheter appears to decrease cesarean section rate and increase the rate of spontaneous vaginal delivery. ${ }^{6}$ 


\section{METHODS}

This is a prospective, comparative clinical study undertaken in the department of obstetrics and gynecology at Tata Main Hospital, Jamshedpur over a period of one year from November 2015 to November 2016. A total of 140 women fulfilling the inclusion criteria were enrolled for this study. They were randomly distributed into 2 groups, Group 1 (Foley's catheter group) and Group 2 (PGE2 gel group) with 70 women included in each group.

\section{Inclusion criteria}

- Primigravida having unfavorable cervix (Bishop's score $<6$ ) with singleton pregnancy at 37 weeks

- Cephalic presentation

- Intact membrane

- Reassuring fetal heart rate tracing who needed termination of pregnancy for fetal or maternal indications.

\section{Exclusion criteria}

- Patients with premature rupture of membrane

- Polyhydramnios

- Scarred uterus

- Heart disease or known hypersensitivity to prostaglandins.

After proper counseling, written consents were taken. In Group 2, a16 F Foley's catheter was inserted under aseptic conditions into cervical canal and balloon was inflated with $50 \mathrm{ml}$ of water. The catheter was left undisturbed until spontaneous expulsion or no longer than 12 hours. Bishop's score was assessed if catheter is expelled spontaneously and if not expelled in 12 hours, catheter was adjusted to maintain continuous traction. Bishop's score was again assessed after 12 hours and cases were taken as a failure if patient does not go into active labor within $24 \mathrm{hrs}$. Women in PGE2 gel group received PGE2 gel intra-cervically. Before giving next dose, Bishop's scoring was done and if required doses were repeated at 6-8 hours interval to a maximum of 3 doses.

The primary outcome was change in Bishop's score. The secondary outcomes were induction delivery interval, need for augmentation, mode of delivery and neonatal outcome.

\section{Statistical analysis}

Qualitative data was presented as mean and standard deviation. Comparison among the study group was done by unpaired t test as per the results of normality test. Quantitative data was presented as frequency and percentage table. Association among the study groups was assessed by Fisher test, Student-t test and Chi- square test. $\mathrm{P}$ value of less than 0.05 was taken as significant.

\section{RESULTS}

Majority of the patients were between the age of 21-25 years. The mean age of patients was $22.12 \pm 2.78$ years and $22.72 \pm 2.73$ years respectively in group 1 and 2 (Table $1)$.

Table 1: Distribution of patients according to age.

\begin{tabular}{|lllll|}
\hline \multirow{2}{*}{ Age (yrs) } & \multicolumn{2}{l}{ Group 1 } & \multicolumn{2}{l|}{ Group 2 } \\
& \multicolumn{2}{l}{ (Foley's catheter) } & \multicolumn{2}{l|}{ (PGE2 gel) } \\
\cline { 2 - 5 } & $\mathbf{N}$ & $\mathbf{\%}$ & $\mathbf{N}$ & $\mathbf{\%}$ \\
\hline$\leq 20$ & 4 & 5.7 & 6 & 8.6 \\
\hline $21-25$ & 43 & 61.4 & 41 & 58.6 \\
\hline $26-30$ & 21 & 30 & 21 & 31.4 \\
\hline$>30$ & 2 & 2.9 & 1 & 1.4 \\
\hline Total & 70 & 100 & 70 & 100 \\
\hline Mean age & $22.12 \pm 2.78$ & & $22.72 \pm 2.73$ \\
\hline
\end{tabular}

The mean gestational age was $38.4 \pm 1.82$ weeks in group 1 and 37.9 \pm 1.64 weeks in group 2 (Table 2).

Table 2: Distribution of patients according to gestational age.

\begin{tabular}{|lllll|}
\hline $\begin{array}{l}\text { Gestational } \\
\text { age (weeks) }\end{array}$ & \multicolumn{2}{l}{ Group 1 } & \multicolumn{2}{l|}{ Group 2 } \\
& N & \% & N & \% \\
\hline$<37$ & 0 & - & 1 & 1.4 \\
\hline $37-39$ & 48 & 68.5 & 46 & 65.7 \\
\hline $40->40$ & 22 & 31.5 & 23 & 32.9 \\
\hline Total & 70 & 100 & 70 & 100 \\
\hline Mean age & $38.4 \pm 1.82$ & $37.9 \pm 1.64$ \\
\hline
\end{tabular}

The most common indication for induction of labor in the present study was pregnancy induced hypertension which constituted $27(38.6 \%)$ in group 1 and $26(37.1 \%)$ in group 2.

Table 3: Change in Bishop score.

\begin{tabular}{|lll|ll|}
\multirow{2}{*}{ Bishop Score } & \multicolumn{2}{l}{ Group 1 } & \multicolumn{2}{l}{ Group 2 } \\
& (Foley's catheter) & (PGE2 gel) \\
& Mean & SD & Mean & SD \\
\hline Pre-induction & 1.74 & 0.27 & 1.48 & 0.82 \\
\hline Post-induction & 8.04 & 1.01 & 7.42 & 1.98 \\
\hline
\end{tabular}

Table 4: Student t-test between groups (Group 1 vs. Group 2).

\begin{tabular}{|lllllll|}
\hline L5\% CI & & & df & $\begin{array}{l}\text { Std. Error } \\
\text { of Diff }\end{array}$ & p value \\
\hline 0.056 & 0.464 & 2.519 & 138 & 0.103 & $\mathrm{p}<0.05^{*}$ \\
\hline-1.145 & -0.095 & 2.33 & 138 & 0.266 & $\mathrm{p}<0.05^{*}$ \\
\hline
\end{tabular}

Other indications for induction of labor were post-dated pregnancy, FGR, decreased fetal movement, oligohydramnios etc. In the present study, there was a significant increase in post-induction Bishop's score in 
both the study groups. However, it was observed that post-induction Bishop's score and mean change in Bishop's scores were significantly higher in Foley's catheter group as compared to PGE2 gel group (Table 4).

Table 5: Need for augmentation.

\begin{tabular}{|lll|}
\hline $\begin{array}{l}\text { Need for } \\
\text { augmentation }\end{array}$ & $\begin{array}{l}\text { Group 1 (Foley's } \\
\text { catheter) }\end{array}$ & $\begin{array}{l}\text { Group 2 } \\
\text { (PGE2 gel) }\end{array}$ \\
\hline Spontaneous & $18(25.7 \%)$ & $21(30 \%)$ \\
\hline ARM & $6(8.6 \%)$ & $7(10 \%)$ \\
\hline Oxytocin & $26(37.1 \%)$ & $28(40 \%)$ \\
\hline ARM+Oxytocin & $20(28.6 \%)$ & $14(20 \%)$ \\
\hline
\end{tabular}

In group 1, 8.6\% patients required ARM, 37.1\% patients required oxytocin and $28.6 \%$ patients required both ARM + oxytocin whereas in group 2, need for augmentation of labor was required by doing ARM in $10 \%$, oxytocin infusion in $40 \%$ and both ARM + oxytocin in $20 \%$. Spontaneous labor ensued in $25.7 \%$ patients in group 1 as compared to $30 \%$ patients in group 2. However, there was no significant difference in both groups as per Chisquare test $(\mathrm{p}>0.05)$ (Table 5).

The rate of vaginal delivery was $80 \%$ and $78.6 \%$ in group 1 and group 2 respectively. Mode of delivery is shown in Table 6. The induction to delivery interval was significantly lower for group 1 as compared to group 2 (Table 7).

Table 6: Comparison of mode of delivery.

\begin{tabular}{|lll|}
\hline Mode of delivery & $\begin{array}{l}\text { Group1 (Foley's } \\
\text { catheter) }\end{array}$ & $\begin{array}{l}\text { Group } 2 \\
\text { (PGE2) }\end{array}$ \\
\hline Forceps & $3(4.3 \%)$ & $2(2.8 \%)$ \\
\hline LSCS & $7(15.7 \%)$ & $13(18.6 \%)$ \\
\hline Vaginal & $40(80 \%)$ & $55(78.6 \%)$ \\
\hline
\end{tabular}

Table 7: Comparison of induction-delivery interval.

\begin{tabular}{|lcccc|c|} 
& \multicolumn{2}{c}{ Group 1 } & \multicolumn{2}{c|}{ Group 2 } & p-value \\
\hline $\begin{array}{l}\text { Induction } \\
\text { delivery }\end{array}$ & 12.2 & 4.8 & 15.47 & 5.3 & $\mathrm{p}<0.05$ \\
interval & & & & & \\
\hline
\end{tabular}

Table 8: Comparison of neonatal outcomes (APGAR SCORE at 1 and 5 minutes) between both groups.

\begin{tabular}{|lllll|}
$\begin{array}{l}\text { Apgar } \\
\text { score }\end{array}$ & $\begin{array}{l}\text { Group1 (Foley's } \\
\text { catheter) }\end{array}$ & \multicolumn{2}{c|}{ Group 2 (PGE2 gel) } \\
\hline$<7 / 10$ & $5(7.1 \%)$ & $0(0 \%)$ & $6(8.6 \%)$ & $1(1.4 \%)$ \\
\hline$>7 / 10$ & 65 & 70 & 64 & 1.4 \\
& $(92.9 \%)$ & $(100 \%)$ & $(91.4 \%)$ & $(98.6 \%)$ \\
\hline
\end{tabular}

There was no significant difference in 1 and 5 minutes APGAR score between the two groups (Table 8). Incidence of side effects was $1.4 \%$ in Foley's catheter group and $5.7 \%$ in PGE2 gel group.

\section{DISCUSSION}

This study compared intra-cervical Foley's catheter with PGE2 gel for pre-induction cervical ripening. In present study, the mean age of patients were $22.12 \pm 2.78$ years and $22.72 \pm 2.73$ years and mean gestation age were $38.4 \pm 1.82$ weeks and 37.9 \pm 1.64 weeks in Foley's catheter group and PGE2 gel group respectively which is comparable with the study done by Dharmavijaya $\mathrm{MN}$ et al who also found similar results. ${ }^{7}$ In present study, the most common indication for induction of labor was pregnancy induced hypertension followed by postdated pregnancy. This is similar to the study conducted by Laddad MM et al. ${ }^{8}$

The mean pre- induction and post- induction Bishop's score were $2.47 \pm 0.65$ and $8.9 \pm 1.45$ in Foley's catheter group whereas in PGE2 group, they were $2.38 \pm 0.78$ and $8.22 \pm 1.60$ respectively. P-value of pre-induction Bishop's score was 0.4597 which was statistically insignificant whereas the p-value of post induction bishop's score was 0.0094, which was statistically significant. The mean change in Bishop's score in Foley's group was $6.45 \pm 1.06$ and that in PGE2 gel group was $5.85 \pm 1.35$ and this difference was considered statistically significant $(\mathrm{p}=0.004)$. Results are comparable to study conducted by Sciscione AC et al where the mean of post-induction Bishop's score in Foley's group was $6.5 \pm 1.63$ and in PGE2 gel group was 5.1 2.3 with $\mathrm{p}$ value $<0.0001$ (statistically significant) and mean change in Bishop's score (3.5 vs 2.7, p=0.015) is significantly higher in Foley's group. ${ }^{9}$ Another study conducted by St Ongo RD et al showed mean change in Bishop's score in Foley's group was $4.8 \pm 0.5$ and in PGE2 gel group was $4.1 \pm 0.5$ with $\mathrm{p}$ value $<0.001$, which was statistically significant. $^{3}$

Induction delivery interval was significantly shorter $(\mathrm{p}<0.05)$ in women who underwent cervical ripening with Foley's catheter. In some studies, it was found to be longer in Foley's catheter group than PGE2. ${ }^{10,11}$ However another study reported more efficacy of Foley's catheter expressed as a lower induction to delivery interval. ${ }^{12,13}$

Present study findings demonstrate no significant difference in oxytocin augmentation in both groups, however some studies have shown an increased need for oxytocin induction and/or augmentation of labor after Foley's ripening, compared with PGE2. ${ }^{14}$ Both methods are similar in terms of the mode of delivery, but the risk of excessive uterine activity is higher with PGE2 group compared with Foley's group.

Neonatal outcome in this study included birth weight, APGAR score at 1 and 5 minutes and admission to NICU. Both methods of inductions are safe for neonates without major difference in neonatal outcome. These results are similar to previous studies. ${ }^{15}$ 
In PGE2 gel group one patient had tachysystole, one patient had vomiting, one had diarrhea and one developed fever whereas in Foley's group one patient developed fever. Overall incidence of side effects was higher in PGE2 gel group $(5.7 \%$ vs $1.4 \%$ with $p$ value $<0.05)$ (statistically significant) which is consistent with the study done by Penagaluru et al. ${ }^{16}$

\section{CONCLUSION}

The results of this study confirm that both PGE2 gel and intra-cervical Foley's catheter are effective methods for pre-induction cervical ripening. However, with Foley's catheter there was significant improvement in Bishop's score and shorter induction delivery interval as compared to PGE2 gel. Foley catheter for cervical ripening is a far cheaper option to PGE2 in term of medicinal/device cost. Because of low cost and easy storage, it is suitable for developing countries with low resources and in settings with limited monitoring facilities. It also has the advantage of simplicity, reversibility and lack of systemic as well as serious side effects.

Funding: No funding sources Conflict of interest: None declared

Ethical approval: The study was approved by the Institutional Ethics Committee

\section{REFERENCES}

1. Walker S, van Rijn BB, Macklon NS, Howe DT. PLD. 31 The rising rate of labour induction: what is causing the trend?. Arch Dis Childhood-Fetal Neonatal Ed. 2014;99(Suppl 1):A115.

2. National Institute for Clinical Excellence. Clinical guidelines for induction of labour, Appendix-E. London: NICE; 2001.

3. Onge RD, Connors GT. Preinduction cervical ripening: a comparison of intracervical prostaglandin E2 gel versus the Foley catheter. Am J Obstetr Gynecol. 1995;172(2):687-90.

4. Embrey MP, Mollison BG. The unfavourable cervix and induction of labour using a cervical balloon. BJOG: Int J Obstetr Gynaecol. 1967;74(1):44-8.

5. Gu N, Ru T, Wang Z, Dai Y, Zheng M, Xu B, et al. Foley catheter for induction of labor at term: an open-label, randomized controlled trial. PloS one. 2015;10(8):e0136856.

6. James C, Peedicayil A, Seshadri L. Use of the Foley catheter as a cervical ripening agent prior to induction of labor. Int $\mathrm{J}$ Gynecol Obstet. 1994;47(3):229-32.
7. Dharmavijaya MN, Umashankar KM, Kavitha G, Nagpure AG, Comparative study of intra-cervical Foley's catheter and PGE2 gel for pre-induction cervical ripening. Int $\mathbf{J}$ Basic and applied Med Sci. 2013;3(1): 247-53.

8. Laddad MM, Kshirsagar NS, Karale AV. A prospective randomized comparative study of intracervical Foley's catheter insertion versus PGE2 gel for pre-induction cervical ripening. Int $\mathrm{J}$ Reprod Contracept Obstetr Gynecol. 2016;2(2):217-20.

9. Sciscione AC, McCullough H, Manley JS, Shlossman PA, Pollock M, Colmorgen GH. A prospective, randomized comparison of Foley catheter insertion versus intracervical prostaglandin E2 gel for preinduction cervical ripening. Am J Obstetr Gynecol. 1999;180(1):55-9.

10. Deshmukh VL, Yelikar KA, Deshmukh AB. Comparative Study of Intra-cervical Foley's Catheter and PGE 2 Gel for Pre-induction Ripening (Cervical). J Obstetr Gynecol India. 2011;61(4):418.

11. Revathi V, Archana I. A Comparative study of efficacy of intracervical prostaglandin E2 gel and intracervical Foley's catheter for pre-induction cervical ripening. J Dental Med Sci (IOSR-JDMS). 2015;14(4):42-6.

12. Dalui R, Suri V, Ray P, Gupta I. Comparison of extraamniotic Foley catheter and intracervical prostaglandin E 2 gel for preinduction cervical ripening. Acta Obstetr Gynecol Scandinav. 2005;84(4):362-7.

13. Schreyer P, Sherman DJ, Ariely S, Herman A, Caspi E. Ripening the highly unfavorable cervix with extraamniotic saline instillation or vaginal prostaglandin E2 application. Obstetr Gynecol. 1989;73(6):938-42.

14. Al-Taani MI. Comparison of prostaglandin E. Eastern Mediterranean Health J. 2004;10(4/5):547.

15. Ghezzi F, Massimo F, Raio L, Di Naro E, Balestreri D, Bolis P. Extra-amniotic Foley catheter and prostaglandin E2 gel for cervical ripening at term gestation. Eur J Obstetr Gynecol Reprod Biol. 2001;97(2):183-7.

16. Penaguluru R, Yaragani P, Padmaja P. comparative study of intra-cervical Foley ${ }^{e c}$ s catheter and intracervical PGE2 gel for pre-induction ripening of cervix. Int J Contemp Med Res. 2016;3(2):410-3.

Cite this article as: Murmu S, Dwivedi C. A comparative study of intracervical Foley's catheter and intracervical PGE2 gel for pre-induction cervical ripening. Int J Reprod Contracept Obstet Gynecol 2018;7:3122-5. 